\title{
Prebiotics and bioactive natural substances induce changes of composition and metabolic activities of the colonic microflora in cancerous rats
}

\author{
Emília Hijová, Alojz Bomba, Izabela Bertková, Ladislav Strojný, Viktória Szabadosová and \\ Alena Šoltésová \\ Institute of Experimental Medicine, Faculty of Medicine, P. J. Šafárik University, Košice, Slovak Republic
}

\begin{abstract}
Prebiotics are defined as selectively fermented food ingredients that induce specific changes in the composition and/or activity in the gastrointestinal microbiota beneficial to the host well-being and health. The aim of the presented experiment was to investigate the effect of a prebiotic applied alone or in combination with Hyppocastani extractum siccum, and Lini oleum virginale in rats with dimethylhydrazine induced colon cancer. Wistar albino rats were fed high fat diet supplemented with the prebiotic alone or in combination with Horse chestnut and flaxseed oil. The activity of faecal glycolytic enzymes, lipid parameters, bile acids, short chain fatty acids and counts of coliforms and lactobacilli were determined. Treatment with the prebiotic alone and in combination with selected substances significantly decreased the activity of glycolytic bacterial enzyme $\beta$-glucuronidase $(P<0.001)$ and increased activities of $\beta$-galactosidase and $\beta$-glucosidase. Bile acids concentration was significantly decreased $(P<0.01)$ except for the combination of the prebiotic with Horse chestnut. The prebiotic alone decreased the lipid parameters $(P<0.001)$ and enhanced production of short chain fatty acids. Application of prebiotic and bioactive natural substances significantly reduced number of coliforms $(P<0.05)$. Prebiotic alone significantly increased the count of lactobacilli $(P<0.05)$. These results show that prebiotics have a protective effect and may be the useful for colon cancer prevention and treatment.
\end{abstract}

Keywords: colon cancer, prebiotic, flaxseed oil, Horse chestnut, rats

Received: 03 November, 2011; revised: 23 February, 2012; accepted: 30 March, 2012; available on-line: 27 April, 2012

\section{INTRODUCTION}

Colorectal cancer (CRC) is among the most frequent tumors worldwide (World Health Statistics, 2008). Lifestyle factors, especially dietary intake, affect the risk of CRC development. Suitable risk biomarkers are required in order to assess the effect that specific dietary components have on CRC risk. In order to achieve optimal digestion, absorption, and nutritional health, we must harbor appropiate microflora. In this context, dietary ingredients improving intestinal function and ensuring a healthy gastrointestinal tract environment attract a great deal of interest. One of the mechanisms increasing the number and metabolic activities of purportedly beneficial microbes (e.g., lactic acid bacteria, bifidobacteria) in the gut is ingestion of prebiotics. Prebiotics are generally defined as nondigestible food ingredients that beneficially affect the host by selectively stimulating the growth or activity of health-promoting lactobacilli and bifidobacteria, may enhance defence mechanisms of the host, increase resistance to various health challenges and accelerate recovery of gastrointestinal tract disturbances. Prebiotics can complement function of probiotics and as synbiotics might represent novel therapeutic or preventive agents (Geier et al., 2006; Trafalska et al., 2006; Rafter et al., 2007).

The aim of the present study was to obtain information about the efficacy of the prebiotic inulin applied alone or in combination with Hyppocastani extractum siccum as nutritional plant extract or Lini oleum virginale on the activities of the bacterial glycolytic enzymes, lipid parameters, bile acids, short chain fatty acids (SCFA), and counts of coliforms and lactobacilli in rats with dimethylhydrazine (DMH) induced colon cancer.

\section{MATERIALS AND METHODS}

Animals. Wistar albino rats $(\mathrm{n}=60)$ (central vivarium, Faculty of Medicine, P. J. Šafárik University), six months old with mean body weight $372 \pm 15 \mathrm{~g}$ were housed in plastic cages with tops and maintained at $22^{\circ} \mathrm{C}$, on $12 \mathrm{~h}$ light/dark cycle, according to the principles provided in Law No. 23/2009 of the Slovak Republic for the Care and Use of Laboratory Animals. Animals were fed high fat diet (HF) containing 10 percent fat (Biofer, Slovak Republic), similar to the diet of some western populations at risk for colon cancer, supplied with drinking water ad libitum. All rats were additionally treated with N,N-dimethylhydrazine (DMH, Merck, Germany). Food and water consumption were monitored daily. The rats were divided into 5 groups of 12 animals each. Control group (CG) was a group fed HF diet with DMH, without administration of prebiotic or bioactive food components. Animals in all experimental groups (EG) were fed $\mathrm{HF}$ diet with $\mathrm{DMH}$ and treated with selected bioactive food components. Experimental group 1 (EG1=PRE) was administered the prebiotic inulin (PRE), experimental group 2 (EG2=PRE+HES) was administered a combination of the prebiotic and Hypocastani extractum sic-

e-mail: hijova@pobox.sk

Abbreviations: $\mathrm{CRC}$, colorectal cancer; $\mathrm{DMH}$, dimethylhydrazine; SCFA, short chain fatty acids; HF, high fat diet; CG, control group; EG, experimental group; PRE, prebiotic; HES, hyppocastani extractum siccum; $O$, lini oleum virginale; PUFA, polyunsaturated fatty acids; $\beta$-GAL, $\beta$-galactosidase; $\beta$-GLUCUR, $\beta$-glucuronidase; $\beta$-GLU, $\beta$-glucosidase. 
Table 1. Activity of bacterial enzymes in faeces in control and experimental groups.

Data represent mean \pm standard deviation, ${ }^{*} P<0.05 ;{ }^{* *} P<0.001 ;{ }^{* * *} P<0.001$

\begin{tabular}{llll}
\hline Groups & $\beta-G A L$ & $\beta-G L U C U R$ & $\beta-G L U$ \\
\hline CG & $0.88 \pm 0.20$ & $4.25 \pm 0.52$ & $0.75 \pm 0.28$ \\
EG1 (PRE) & $1.92 \pm 0.37^{*}$ & $0.83 \pm 0.52^{* * *}$ & $1.83 \pm 0.26^{*}$ \\
EG2 (PRE+HES) & $2.00 \pm 0.32^{*}$ & $0.72 \pm 0.25^{* * *}$ & $1.52 \pm 0.16$ \\
EG3 (PRE+O) & $1.70 \pm 0.23^{*}$ & $2.18 \pm 0.33^{* * *}$ & $1.35 \pm 0.39$ \\
EG4 (PRE+HES+O) & $2.11 \pm 0.55^{* *}$ & $2.22 \pm 0.56^{* * *}$ & $1.92 \pm 0.46^{*}$ \\
\hline
\end{tabular}

Statistical significance is comparison between CG versus EG1, EG2, EG3, EG4

cum, experimental group $3(\mathrm{EG} 3=\mathrm{PRE}+\mathrm{O})$ was given a combination of the prebiotic and Lini oleum virginale. Experimental group 4 (EG4=PRE+HES+O) was administered a mixture of all selected substances.

Treatments. Treatment consisted of oligofructose-enriched inulin (PRE, BeneoSynergy 1, ORAFTI, Tienen, Belgium) at a dose of $2 \%$ of $\mathrm{HF}$ diet. It is a commercialized food ingredient composed of a mixture of longchain inulin and short-chain oligofructose. Extract of Aesculus bippocastanum L. (HES, Calendula, Slovak Republic) was administered at a dose of $1 \%$ of HF diet. Most of the beneficial effects of the extract of Aesculus hippocastanum L., (Hippocastanaceae) commonly known as Horse chestnut are attributed to its principal component beta-escin or aescin. Lini oleum virginale (Dr. Kulich Pharma, Czech Republic) is obtained from flaxseed Linum usitatissimum L. containing a high amount of $\omega-3$ polyunsatured fatty acids ( $\omega-3$ PUFA), and was administered at a dose of $2 \%$ of $\mathrm{HF}$ diet.

Two weeks after begining of the experiments, rats were treated with $\mathrm{DMH}$ at a dose of $20 \mathrm{mg} / \mathrm{kg}$ body weight s.c., two times a week, and the dietary treatments were continued for an additional six weeks. Then the rats were anaesthetized (Ketamine $100 \mathrm{mg} / \mathrm{kg}+$ Xylazine $15 \mathrm{mg} / \mathrm{kg}$ body weight i.p.), blood samples were taken from the heart by puncture and feaces samples from the colon.

Biochemical Analysis. Blood samples were centrifuged at $2500 \times \mathrm{g}$ for $15 \mathrm{~min}$ and serum used for determination of bile acids with a commercial kit (Trinity Biotech, Ireland) and lipid parameters with commercial kits (Biolatest, Czech Republic). The measurement was carried out on an automatic spectrophotometric analyser Cobas Mira S (Roche, Schwitzerland). Freshly collected faeces samples were examined for activities of the bacterial glycolytic enzymes - $\beta$-galactosidase ( $\beta$-GAL), $\beta$-glucuronidase $(\beta$-GLUCUR), and $\beta$-glucosidase $(\beta-G L U)$ using an API-ZYM kit (Biomérieux, France). Activities were determined according to the manufacturer's instructions and expressed on the scale of 0 (negative reaction) to 5 (maximum activity). The SCFA were analyzed in the colon contents using gas chromatography (Hewlett Packard 6890 Plus, USA). Total SCFA $(\mathrm{mmol} / 100 \mathrm{ml}$ of wet cecal digesta $)=$ acetic + propionic + butyric + isobutyric + isovaleric + valeric + caproic.

Bacteriological Examination. Microbial analyses (total lactobacilli and coliforms) of the faecal samples were carried out after the completion of the experiment. Faeces (1 g) was placed in a sterile polyethylene Stomacher Lab Blender bag with $9 \mathrm{ml}$ of sterile $0.9 \% \mathrm{NaCl}$. Series of 10 -fold dilutions $\left(10^{-2}\right.$ to $\left.10^{-8}\right)$ were made in the same sterile diluent. From appropriate dilution, 0.1 $\mathrm{ml}$ aliquots were spread onto two selective Mc Conkey agar (Merck, Germany) for coliforms and Rogosa agar (Biocar diagnostic, France) for lactobacilli. The plates for lactobacilli were made anaerobic (Gas PaK, USA) and incubated at $37^{\circ} \mathrm{C}$ for 48 hours. The plates for coliforms were incubated aerobically at $37^{\circ} \mathrm{C}$ for $16-18$ hours. Colonies were counted and bacteria were $\mathrm{Gram}^{-}$stained and viewed under a microscope for morphological characterization. The viable counts are expressed as the log 10 of colony forming units (CFU) per gram of faeces. The colonic $\mathrm{pH}$ was measured using a $\mathrm{pH}$ meter kit with $\mathrm{pH}$ electrode SP 1DT (Merck). The data are presented as mean \pm standard deviation (S.D.). Statistical analysis was performed by Student's $t$-test and analysis of variance (ANOVA) to determine the significance. Values of $P<0.05$ were considered to be statistically significant.

\section{RESULTS}

\section{Weight gain of the rats}

The mean body weight of the rats at the begining of the experiment was $372.57 \pm 15.01 \mathrm{~g}$ and at the end of the experiment it rose to $398.16 \pm 33.19 \mathrm{~g}(P<0.05)$. Respectively, at the end of experiment in the control group the mean body weight increased by $2.1 \%$, by $2.8 \%$ in EG1, by $0.8 \%$ in EG2, by $10.9 \%$ in EG3, and by $17.2 \%$ EG4. Food consumption was changed proportional to body weight of rats.

\section{The effect of treatment on activities of glycolytic enzymes}

The changes in activity of glycolytic enzymes in control group and experimental groups are summarized in Table 1. Inulin treatment alone (EG1) and in combination with bioactive natural substances significantly decreased activity of $\beta$-glucuronidase $(P<0.001)$, and increased activities of $\beta$-galactosidase and $\beta$-glucosidase as compared to the control group. The tendency of changes in activity of glycolytic enzymes was similar in all experimental groups.

\section{The effect of treatment on biochemical parameters and microbial analysis}

In all treated groups a noticably decreased bile acid concentration was detected significantly in EG1, EG3 $(P<0.01)$, and EG4 $(P<0.001)$, and in EG2 nonsignificantly, as shown in Table 2. The total concentration of cholesterol and triacylglycerols was decreased significantly in EG1 $(P<0.001)$, and nonsignificantly in the other experimental groups (Table 2). Changes in composition of short chain fatty acids - acetic, propionic, butyric in control and experimental groups are shown in Table 3. The counts of coliforms and lactobacilli are presented in Table 4. In the control group the count of coliforms was $4.67 \pm 1.03 \log _{10} \mathrm{CFU} / \mathrm{g}$ and of lactobacilli $8.87 \pm 0.65$ 
Table 2. Total cholesterol, triacylgylcerols and bile acids in serum in control and experimental groups.

Data represent mean \pm standard deviation, ${ }^{* *} P<0.001 ;{ }^{* * *} P<0.001$

\begin{tabular}{|c|c|c|c|}
\hline Groups & $\begin{array}{r}\text { Total cholesterol } \\
(\mu \mathrm{mol} / \mathrm{l})\end{array}$ & $\begin{array}{r}\text { Triacylglycerols } \\
(\mu \mathrm{mol} / \mathrm{l})\end{array}$ & $\begin{array}{r}\text { Bile acids } \\
(\mu \mathrm{mol} / \mathrm{l})\end{array}$ \\
\hline CG & $1.39 \pm 0.22$ & $1.05 \pm 0.32$ & $16.84 \pm 6.33$ \\
\hline EG1 (PRE) & $0.83 \pm 0.19 * * *$ & $0.57 \pm 0.23^{* * *}$ & $11.72 \pm 4.22^{* *}$ \\
\hline EG2 (PRE+HES) & $0.94 \pm 0.16^{* * * *}$ & $0.89 \pm 0.68$ & $13.56 \pm 6.07$ \\
\hline EG3 (PRE+O) & $1.05 \pm 0.16$ & $1.13 \pm 0.46$ & $10.84 \pm 3.19^{* *}$ \\
\hline $\mathrm{EG} 4(\mathrm{PRE}+\mathrm{HES}+\mathrm{O})$ & $1.14 \pm 0.16$ & $0.89 \pm 0.54$ & $5.76 \pm 2.66^{* * *}$ \\
\hline
\end{tabular}

Statistical significance is comparison between CG versus EG1, EG2, EG3, EG4

Table 3. Composition of short chain fatty acids in faeces in control and experimental groups.

Total SCFA $\left(\mathrm{mmol} / 100 \mathrm{ml}\right.$ of wet cecal digesta) = acetic + propionic + butyric + isobutyric + isovaleric + valeric + caproic. ${ }^{* *} P<0.01$

\begin{tabular}{lllcl}
\hline Groups & Total SCFA & Acetic & Propionic & Butyric (\% total SCFA) \\
\hline CG & 17.67 & 64.79 & 15.67 & 13.64 \\
EG1 (PRE) & 18.21 & 64.52 & 15.16 & $15.98^{* *}$ \\
EG2 (PRE+HES) & 15.30 & 67.91 & 13.79 & 13.07 \\
EG3 (PRE+O) & 15.10 & 63.37 & 16.88 & 13.44 \\
EG4(PRE+HES+O) & 17.00 & 64.70 & 15.88 & 13.52 \\
\hline
\end{tabular}

Statistical significance is comparison between CG versus EG1, EG2, EG3, EG4

Table 4. Counts of lactobacilli, coliforms and $\mathrm{pH}$ in faeces in control and experimental groups.

Data represent mean \pm standard deviation, ${ }^{*} P<0.05$

\begin{tabular}{llll}
\hline Groups & $\mathrm{pH}$ & Coliforms & Lactobacilli \\
\hline CG & 6.20 & $4.67 \pm 1.03$ & $8.87 \pm 0.65$ \\
EG1 & 6.03 & $3.02 \pm 0.80^{*}$ & $9.56 \pm 0.75^{*}$ \\
EG2 & 6.46 & $3.25 \pm 1.40^{*}$ & $9.12 \pm 0.93$ \\
EG3 & 5.66 & $2.89 \pm 0.25^{*}$ & $9.32 \pm 0.24$ \\
\hline
\end{tabular}

Statistical significance is between CG versus EG1, EG2, EG3, EG4

$\log _{10} \mathrm{CFU} / \mathrm{g}$. The application of the prebiotic alone or in combinations decreased the counts of coliforms and increased counts of lactobacilli in all experimental groups.

\section{DISCUSSION}

Prebiotics are generally defined as nondigestible food ingredients that beneficially affect the host by selectively stimulating the growth and/or activity of one, or a limited number of bacteria in the colon that can improve the host health (Gibson et al., 1995). This definition was updated in 2004 (Gibson et al., 2004) and prebiotics are now defined as selectively fermented ingredients that allow specific changes in the composition and/or activity in the gastrointestinal microbiota that confer benefits upon host well-being and health. In order to be effective, a prebiotic must escape digestion in the upper gastrointestinal tract so that it can be released in the lower tract and used by the beneficial microorganisms in the colon, mainly bifidobacteria and lactobacilli.

Inulins as prebiotic are a group of non-digestible oligosaccharides, fructans. Inulin-type fructans exctracted from chicory roots are prebiotic food ingredients which in the gut lumen are fermented to lactic acid and short chain fatty acids (Hijova et al., 2007; Alvaro et al., 2008). Of these, butyrate and propionate inhibit growth of colon tumour cells and histone deacetylases. Butyrate also causes apoptosis, reduces metastasis in colon cell lines, and protects from genotoxic carcinogens. The elevated butyric acid concentra- tion, and decreased concentrations of total cholesterol and triacylglycerol during experimental period are in accordance with experimental animal models which revealed that inulintype fructans have anticarcinogenic properties (Pool-Zobel et al., 2007), hypolipidaemic effect (Beylot, 2005), and antiatherogenic effects (Rault-Nania et al., 2006). A human intervention study (SYNCAN project) provided experimental evidence that inulin modulates parameters of colon cancer risk in human colon cells (Loo et al., 2005). Activities of the bacterial glycolytic enzymes $\beta$-galactosidase ( $\beta$-GAL), $\beta$-glucuronidase ( $\beta$-GLUCUR), and $\beta$-glucosidase $(\beta-G L U)$ have been determined in this study. Bacterial glycolytic enzyme activities are of relevance for fermentation of nutrients in the large intestine and health of the animal. Diet with a higher load of non-digestible oligosaccharides in the large intestine stimulated higher $\beta$-galactosidase activity. Bacterial $\beta$-galactosidase could also be involved in the hydrolysis of any undigested lactose reaching the large intestine. This enzyme is mainly produced by bifidobacteria and lactobacilli and its increase in large intestine substantiates a stimulatory effect of inulin on lactic acid bacteria (Lay et al., 2004). $\beta$-glucuronidase activity is perceived as harmful for health as it is able to release carcinogens from hepatically derived glucuronic acid conjugates and is a critical factor in the enterohepatic circulation of drugs and other foreign compounds (Salminen et al., 1998). The activity of $\beta$-glucosidase contributes to the hydrolysis of glucose monomers from nonstarch polysaccharides (e.g., cellulose, $\beta$-glucans), but it is also possible for $\beta$-glucosidase to be involved in the formation of toxic aglycons from plant glucosides (Pool-Zobel et al., 2002). An increase in $\beta$-glucosidase activity could potentially be regarded as beneficial due to hydrolysis products of plant glucosides, some of which have more antimutagenic, antioxidative, anticarcinogenic and immune stimulatory properties than the respective glucosides. Therefore, its relevance for animal and human health will also depend upon the nature of dietary plant glucosides. The activity of these enzymes with toxicological importance could be altered by the diet, ultimately potentially decreasing the risk of carcinogenesis (Nalini et al., 2004; Manju et al., 2006).

In our study the number of lactobacilli was the highest in the group treated with the prebiotic alone, but a simi- 
lar tendency was seen in other experimental groups. Coliforms were significantly reduced in the same groups of rats. Current knowledge shows that the colonic microflora is involved in the etiology of colorectal cancer. Intestinal bacteria can produce substances from dietary components that have genotoxic, carcinogenic, and tumour-promoting activities, and human feces have been shown to be genotoxic and cytotoxic to colon cells. The bacteria (e.g., coliforms, clostridia) play an important role in the process of development of colorectal carcinoma. The precise bacterial types associated with colorectal cancer risk have not been elucidated but it is clear that some bacterial groups (lactobacilli and bifidobacteria) have much lower activities of enzymes that can generate carcinogens than do other gut microflora components such as coliforms, clostridia and Bacteroides. This suggests that the balance of microbial types in the gut is important in terms of colorectal cancer risk and beneficial modulation of the intestinal microflora could decrease the colorectal cancer risk.

Most of the beneficial effects of $A$. hippocastanum (Horse chestnut) seed are attributed to its component beta-aescin or aescin; it also contains flavonoids, namely glycosides of quercetin and kaempferol. Beta-aescin is known to generate a wide variety of biochemical and pharmacological effects used in nutraceutical, cosmetic, and food supplement industries. Recent studies suggest that beta-aescin may be used in the treatment of chronic venous insufficiency, edema, hemorrhoids, and may possess anti-inflammatory, chemopreventive, anti-proliferative, apoptotic and anti-obesity efficacy (Patlolla et al., 2006; Niu et al., 2008; Hu et al., 2008). A novel feature found in our study - the positive changes in bacterial enzymes, concentration of bile acids and lipids - confirmed the opinion that Hyppocastani extractum siccum may be a useful candidate agent for colon cancer chemoprevention and treatment. Fatty acid composition of dietary fat plays a vital role in colon tumour development in animal models. Fats containing omega- 6 fatty acids (e.g., corn oil) enhanced and omega-3 fatty acids (e.g., flaxseed oil) reduced chemically induced colon tumour development in rats. Dietary flaxseed is high in lignan content. Lignans are phytoestrogens, good sources of dietary fibre, protein, antioxidant, and other nutritional elements and show preventive role in development of colon cancer tumour in experimental animals and humans (Bommareddy et al., 2006; Theodoratou et al., 2007). Although epidemiological and experimental studies indicate an association of elevated faecal levels of secondary bile acids as well as total bile acids with a high risk of colon cancer development, the cellular mechanism for the actions of bile acids is not clear (Cheng et al., 2005; Hagiwara, 2006). Elevated concentration of bile acids in the control group was significantly reduced by administration of selected nutritional products.

In conclusion, dietary habits have been associated with aetiology and prevention of civilization diseases including colon cancer that represent the most serious health, economic, and social problem. For these reasons, the interest in prevention and therapy using substances of biotechnological and natural origin has been increasing worldwide. Among potentially protective foods, growing attention should be devoted to prebiotics which have health benefits. Results of our experiment show that the prebiotic inulin may be a useful candidate for colon cancer prevention and treatment.

\section{Acknowledgements}

This work was supported by the Agency of the Slovak Ministry of Education for the Structural Funds of the
EU, under project ITMS 26220120058 (50\%) and ITMS $26220220104(50 \%)$.

\section{REFERENCES}

Alvaro A, Sola R, Rosales R, Ribalta J, Anguera A, Masana L, Vallve JC (2008) Gene expression analysis of a human enterocytes cell line reveals downregulation of cholesterol biosynthesis in response to short-chain fatty acids. IUBMB 60: 757-764.

Beylot M (2005) Effects of inulin-type fructans on lipid metabolism in man and in animal models. Br J Nutr 93 (Suppl 1): S163-S168.

Bommareddy A, Arasada BL, Mathees DP, Dwiveli C (2006) Chemopreventive effects of dietary flaxseed on colon tumor development. Nutrition and Cancer 54: 216-222.

Cheng K, Raufman JP (2005) Bile acids-induced proliferation of human colon cancer cell line is mediated by transactivation of epidermal growth factor receptors. Biochem Pharmacol 70: 1035-1047.

Geier MS, Butler RN, Howarth GS (2006) Probiotics, prebiotics and synbiotics: a role in chemoprevention for colorectal cancer? Cancer Biol Therapy 5: 1265-1269.

Gibson GR, Roberfroid MB (1995) Dietary modulation of the human colonic microbiota: Introducing the concept of prebiotics. $J$ Nutr 125: 1401-1412.

Gibson GR, Probert HM, Loo VJ, Rastall RA, Roberfroid MB (2004) Dietary modulation of the human colonic microbiota: updating the concept of prebiotics. Nutr Res Rev 17: 259-275.

Hagiwara T (2006) Bile acids and colorectal cancer. Jpn I Cancer Clinics 51: 919-925.

Hijova E, Chmelarova A (2007) Short chain fatty acids and colonic health. Bratisl Med J 108: 354-358.

Hu JN, Zhu XM, Han LK, Saito M, Sun YS, Yoshikawa M, Kimura Y, Zheng YN (2008) Anti-obesity effects of escins extracted from the seeds of Aesculus turbunata BLUME (Hippocastanaceae). Chem Pharmaceut Bull (Tokyo) 56: 12-16.

Lay C, Sutren M, Lepercq P, Juste C, Rigottier-Gois L, Lhoste E, Lemee R, Le Ruyet P, Done J, Andieux C (2004) Influence of Camembert consumption on the composition and metabolism of intestinal microbiota. A study in human microbiota-associated rats. $\mathrm{BrJ}$ Nutr 92: 429-438.

Loo VJ, Clune Y, Bennett M, Collins JK (2005) The SYNCAN project: goals, set-up, first results and setting of the human intervention study. Br I Nutr 93 (Suppl 1): S91-S98.

Manju V, Nalini N (2006) Effect of ginger on bacterial enzymes in 1,2-dimethylhydrazine induced experimental colon carcinogenesis. Eur I Cancer Prev 15: 377-383.

Nalini N, Manju V, Menon VP (2004) Effect of coconut cake on the bacterial enzymes activity in 1,2-dimethylhydrazine induced colon cancer. Clin Chim Acta 342: 203-210.

Niu YP, Li LD, Wu LM (2008) Beta-aescin: A potent natural inhibitor of proliferation and inducer of apoptosis in human chronic myeloid leukemia K562 cells in vitro. Leukemia and Lymphoma 29: 1-8.

Patlolla JM, Raju J, Swamy MV, Rao CV (2006) Beta-eascin inhibits colonic aberrant crypt foci formation in rats and regulates the cell cycle growth by inducing p21 (waf1/cip1) in colon cancer cell. Mol Cancer Ther 5: 1459-1466.

Pool-Zobel BL, Loo JV, Rowland IR, Roberfroid, MB (2002) Experimental evidences on the potential of prebiotic fructans to reduce the risk of colon cancer. Br J Nutr 87: S273-S281.

Pool-Zobel BL, Sauer I (2007) Overview of experimental data on reduction of colorectal cancer risk by inulin-type fructans. J Nutr 137: 2580S-2584S.

Rafter J, Bennett M, Caderni G, Clune Y, Hughes R, Karlsson PC, Klinder A, O’Riordani M, Sullivan GC, Pool-Zobel B, Rechkemmer G, Roller M, Rowland I, Salvadori M, Thijs H, Loo VJ, Watzl B, Collins JK (2007) Dietary synbiotics reduce cancer risk factors in polypectomized and colon cancer patients. Am J Clin Nutr 85: 488-496.

Rault-Nania MH, Gueux E, Demougeot C, Demigne Ch, Rock E, Mazur A (2006) Inulin attenuates atherosclerosis in apolipoprotein Edeficient mice. BrJ Nutr 96: 840-844.

Salminen S, Bouley C, Boutron-Ruault MC, Cummings JH, Franck,A, Gibson GR, Isolauri E, Moreau MC, Roberfroid MB, Rowland IR (1998) Functional food science and gastrointestinal physiology and function. Br J Nutr 80: S147-S171.

Theodoratou E, McNeill G, Cetnarsky R, Farrington SM, Temesa A, Barnetson R, Porteous M, Dunlop M, Campbell H (2007) Dietary fatty acids and colorectal cancer: a case-control study. Am J Epidemiol 166: 181-195.

Trafalska E, Grzybowski A (2006) Probiotics and prebiotics in prevention of chronic civilization diseases. New Medicine 9: 3-6.

World Health Statistics (2008): WHO Press, Geneva, Switzerland, pp 110. 